\title{
A Mimicker of Gallbladder Carcinoma: Cystic Gastric Heterotopia with Intestinal Metaplasia
}

\author{
Gonca ÖZGÜN ${ }^{1}$, Şaduman BALABAN ADIM' ${ }^{1}$, Nesrin UĞRAŞ ${ }^{1}$, Sadık KILIÇTURGAY² \\ Department of ${ }^{1}$ Pathology and ${ }^{2}$ General Surgery, Uludağ University, Faculty of Medicine, BURSA, TURKEY
}

\begin{abstract}
Heterotopic gastric mucosa in the gallbladder is an unusual entity and is usually clinically silent. We report a 75-year-old female patient who presented with intermittent upper abdomial pain radiating to the back. Abdominal imaging studies showed a sessile polypoid lesion and a gallstone in the gallbladder. Gallbladder carcinoma was suspected and cholecystectomy performed. Intraoperative frozen section examination suggested mucinous tumor, suspicious for malignancy. However, the permanent sections revealed aberrant gastric tissue consisted of gastric pyloric and fundic glands of heterotopic gastric mucosa with intestinal metaplasia in the gallbladder.
\end{abstract}

Key Words: Choristoma, Gastric mucosa, Gallbladder, Carcinoma, Differential diagnosis

\section{INTRODUCTION}

Heterotopia is defined as the occurrence of histologically normal tissue in an abnormal location, which makes a mass of tissue that is histologically normal for some part of the body other than the site which it is located (1). Heterotopic tissue of various types in the gallbladder has been described in the literature, including gastric mucosa, pancreatic tissue, liver tissue, and others such as adrenal and thyroid tissue (2). Heterotopic gastric mucosa can be found anywhere in the alimentary tract from the tongue to the rectum, however, heterotopic gastric mucosa in the gallbladder is a rare entity $(3,4)$. Heterotopic gastric mucosa, as well as intestinal metaplasia in the gallbladder, may be one of the causes of gallbladder cancer (3).

\section{CASE REPORT}

A 75-year-old woman was admitted our hospital with a one-year history of intermittent upper abdominal pain radiating to the back. There was no history of jaundice. The physical examination revealed tenderness in the right upper quadrant with deep palpation. Abdominal ultrasonography and computerized tomography demonstrated a sessile polypoid lesion measuring $29 \mathrm{~mm}$ in its largest axis in the fundus of the gallbladder and a gallstone measuring $9 \mathrm{~mm}$ in its largest axis. Cholecystectomy was performed.

Cholecystectomy specimen was sent to the pathology laboratory for frozen section examination. On gross examination, the gallbladder specimen measured $13 \times 4 \times 1$ $\mathrm{cm}$ with a smooth serosal surface. There was a $2 \times 2 \times 1 \mathrm{~cm}$

(Turk Patoloji Derg 2017, 33:58-61)

Received : 22.02.2012 Accepted : 15.08.2012 firm polypoid lesion at the fundus of the gallbladder. On cut sections of the polypoid lesion, milimetrical cystic spaces containing yellowish fluid were seen. The gallbladder wall was slightly thickened and one gallstone $1 \mathrm{~cm}$ in size was found.

Frozen specimen suggested a diagnosis of 'mucinous tumor, differentiation for malignancy will be held from the permanent slides' (Figure 1A,B). Because of the diagnosis from the frozen examination, liver segment 5 resection was performed in the same surgical session. The histologic examination of the permenant slides revealed that the polypoid lesion was within the lamina propria and consisted of heterotopic gastric mucosa, containing both fundic type glands with parietal cells and pyloric type glands. Some of the glands were cystically dilated and extensive mucin secretion from the glands was seen (Figure 2A-D, Figure 3). Histochemically, Periodic Acid Schiff/Alcian Blue $\mathrm{pH}$ 2.5 (PAS/AB pH 2.5) stain showed frequent PAS (+) neutral mucin and High Iron Diamine/Alcian Blue pH 2.5 (HID/ $\mathrm{AB} \mathrm{pH}$ 2.5) stain showed sulfomucin and that there were intestinal metaplasia foci characterised by sialomucin containing goblet cells (Figure 4A,B). The gastric mucosa showed no ulceration or Helicobacter pylori. Liver sections showed no lesions except sinusoidal dilatation and minimal congestion.

\section{DISCUSSION}

The presence of heterotopic gastric mucosa in gallbladder first described in 1934 (5), although widely described in the literature, it still appears to be a very rare condition in

Correspondence: Gonca ÖZGÜN

Uludağ Üniversitesi, Tip Fakültesi, Patoloji Anabilim Dalı, BURSA, TURKEY

E-mail: goncabarit@hotmail.com Phone: +90 2242953680 

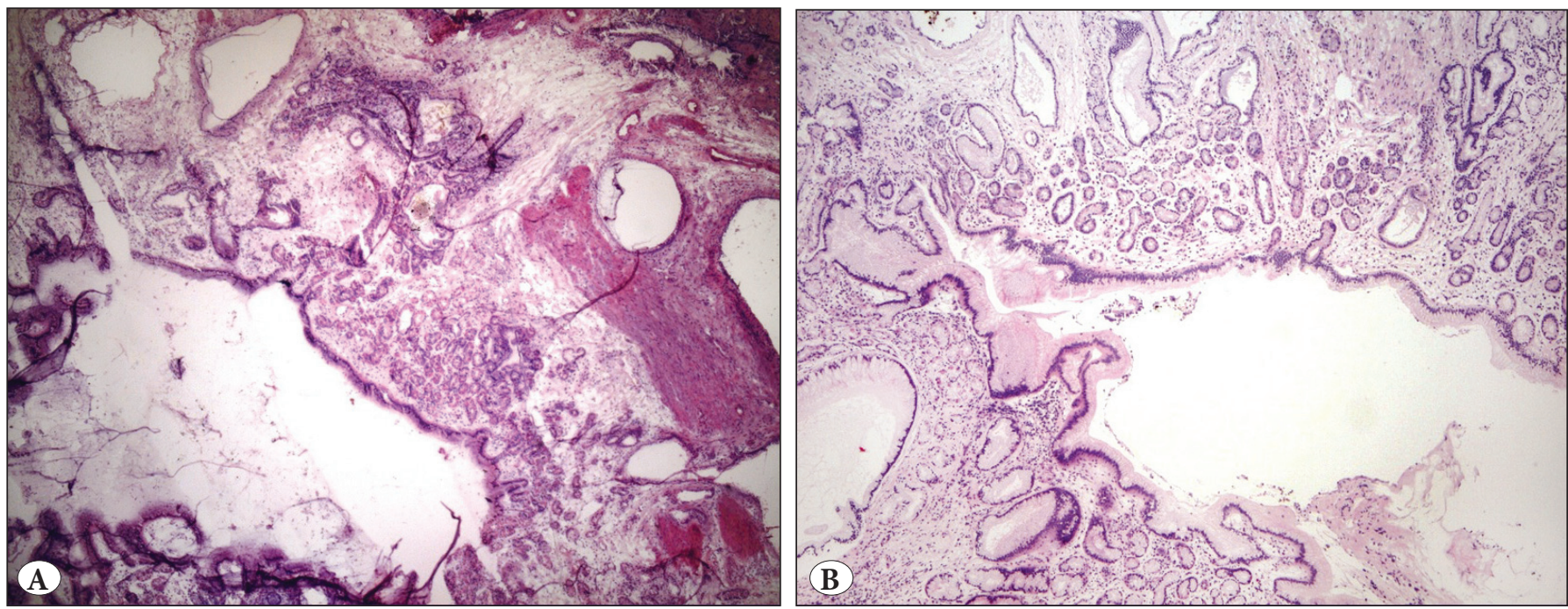

Figure 1: A) Frozen section of the lesion in the gallbladder showed cystically dilated glands with mucinous epithelium in the lamina propria (H\&E; $\mathrm{x} 25)$. B) On permanent slides of the same area, there were cystically dilated glands with mucinous epithelium and fundic type glands in the surrounding area (H\&E; x25).
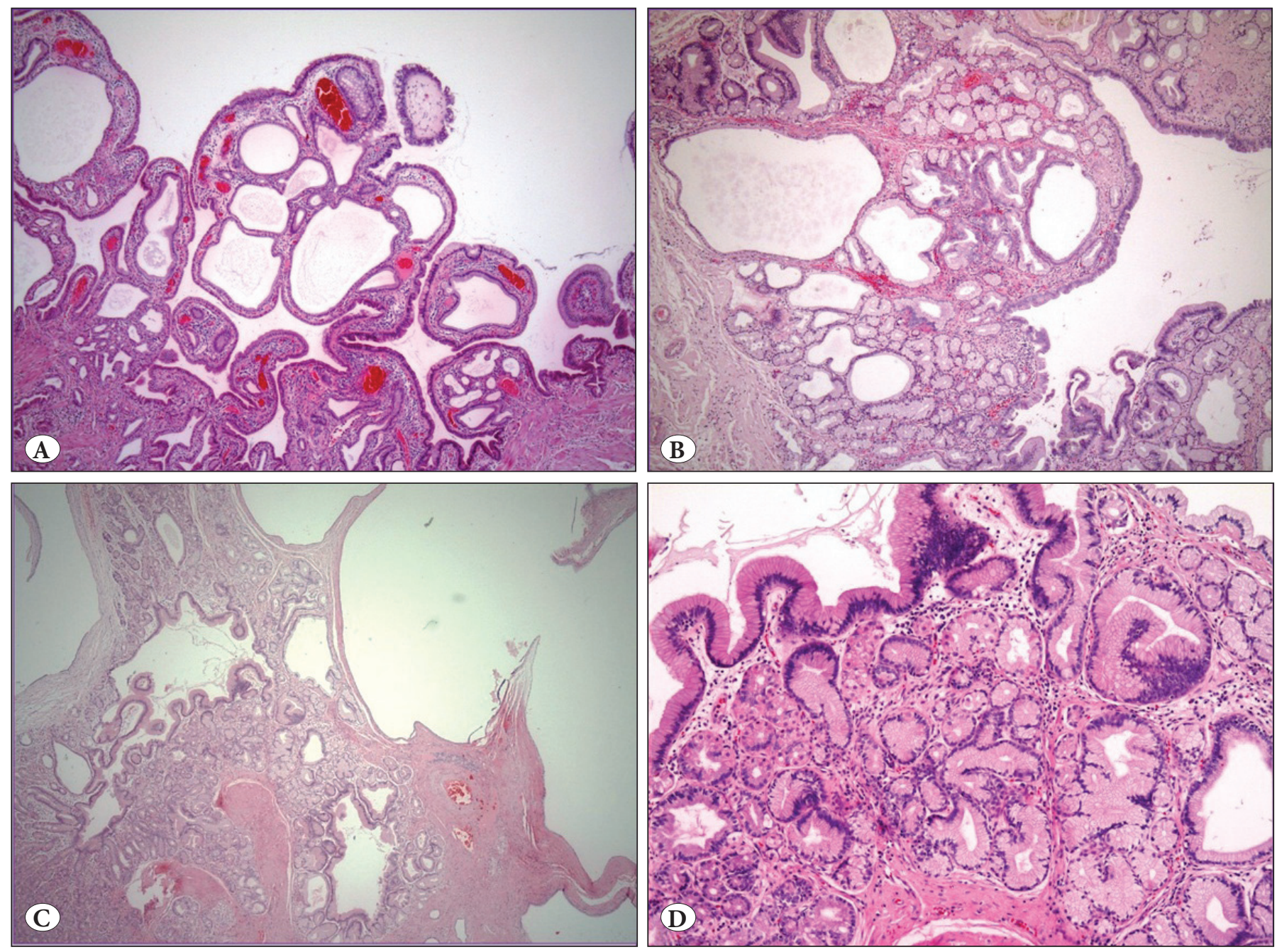

Figure 2: Different areas of the polypoid lesion of the gallbladder. A) H\&E; x25, B) H\&E; x25, C) H\&E; x25, D) H\&E; x40. 
the gallbladder (6). Unlike metaplasia, gastric heterotopia is thought to be a developmental anomaly. Multipotential cells in the embryonic primitive foregut endoderm give rise to the epithelial mucosal lining of the upper gastrointestinal tract (3).

The lesion is often discovered incidentally, but when symptoms are reported, nausea, vomiting, and upper quadrant abdominal pain seem to be the most common symptoms (7). Heterotopic gastric mucosa is either incidentally found in the gallbladder that has undergone cholecystectomy due to cholelithiasis or cholecystitis, or recognized as a polypoid lesion at abdominal ultrasonography (8). The diagnosis of gastric heterotopia can be made preoperatively by the use of pertechnetate scintigraphy, associated with $\mathrm{H}_{2}$ receptor blocking agent (3). The differential diagnosis of gastric heterotopia in

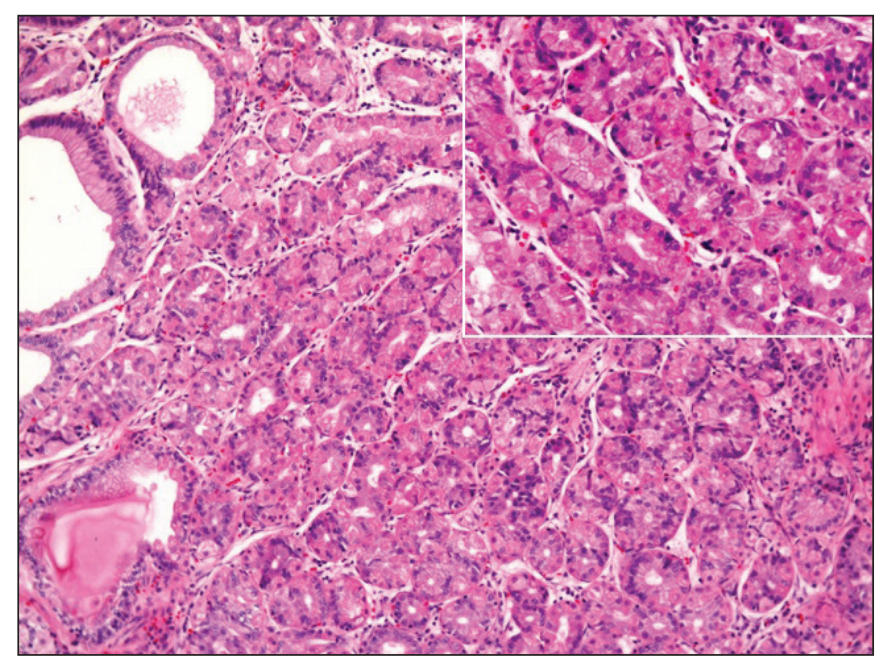

Figure 3: Fundic glands characterized by parietal and chief cells were present (H\&E; x100, inset: $\mathrm{H} \& \mathrm{E} ; \mathrm{x} 200)$.

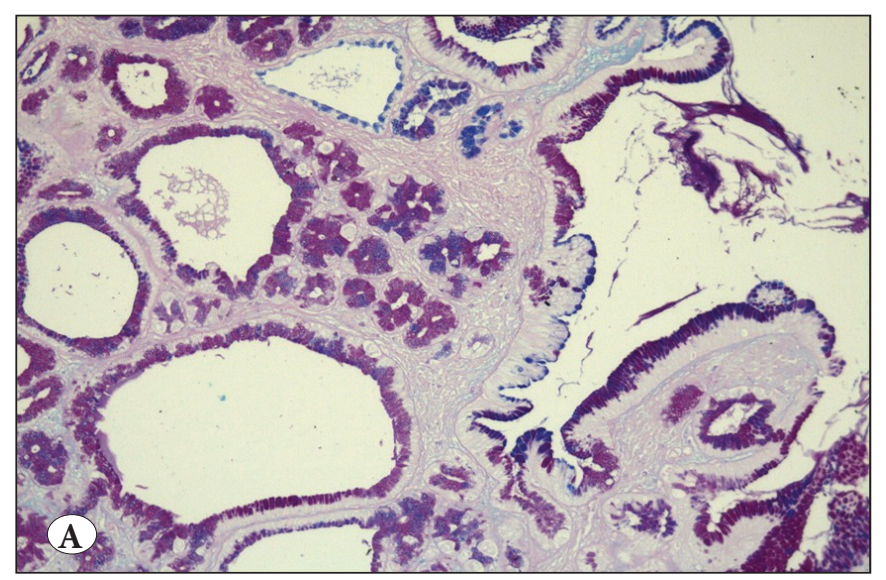

gallbladder includes fixed gallstones, intestinal metaplasia that sometimes also has a polypoid configuration, pyloric gland metaplasia and benign or malignant neoplasms (9).

Microscopically, the most characteristic features of gastric heterotopia are the presence of fundic glands with parietal and chief cells and pyloric type mucous glands. Those findings help to differentiate gastric heterotopia from gastric metaplasia in gallbladder, which is a common finding in chronic cholecystitis. Gastric metaplasia in gallbladder is composed of only pyloric glands (4).

Carcinoma must be ruled out especially in polypoid lesions of the gallbladder measuring larger than $1 \mathrm{~cm}$. The incidence of gallbladder carcinoma in sessile polypoid lesions is particularly high (10). As in our case, this disease may be suspected for gallbladder carcinoma clinically and also in frozen sections. According to the literature, excluding the cases with lesions found incidentally on histologic examination, a preoperatively identified lesion was found in 30 cases: in 14 cases, gallbladder carcinoma was suspected; in 13 cases the preoperative diagnosis was 'gallbladder tumor' without a description, in 3 cases the preoperative diagnosis was a benign lesion, such as adenoma or cholelithiasis (6). In well-differentiated carcinomas, the glands are lined by columnar to cuboidal tumor cells resembling those of normal gallbladder. Occasional goblet, Paneth or endocrine cells may be seen. The cells arranged in cords, glands or sheets. Approximately $12 \%$ of the gallbladder carcinomas are of mucinous type. The tumor cells are often arranged in small clusters and are surrounded by large pools of mucin (11). Although there were some closely packed glands, none of the cells seemed malignant either cytologically or architecturally in our case.

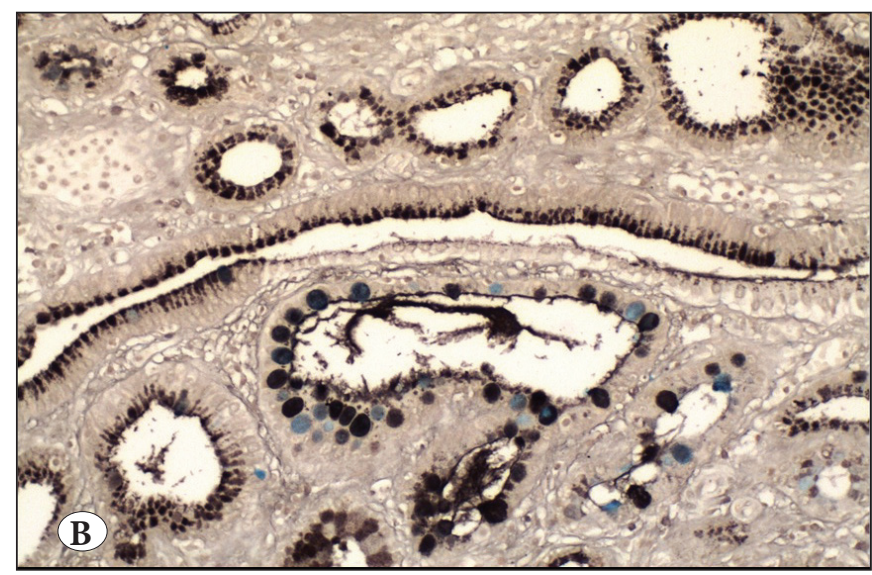

Figure 4: A) Histochemically, Periodic Acid Schiff/Alcian Blue pH 2.5 stain showed frequent PAS (+) neutral mucin (pink in color) and intestinal metaplasia foci characterized by sialomucin containing goblet cells (blue in color) (PAS/AB pH $2.5 \times 40$ ). B) High Iron Diamine/Alcian Blue pH 2.5 stain showed sulfomucin content of some of the goblet cells (HID/AB pH $2.5 \times 40$ ). 
In conclusion, from a clinical point of view, it can be difficult to manage the polypoid lesions in the gallbladder and to rule out the possibility of cancer preoperatively. One should be careful when the gastric glands are cystically dilated and contain extensive mucin on intraoperative frozen section examination.

\section{REFERENCES}

1. Kalman PG, Stone RM, Phillips MJ. Heterotopic gastric tissue of the bile duct. Surgery. 1981;89:384-6.

2. Madrid C, Berrocal T, Gorospe L, Prieto C, Gamez M. Heterotopic gastric mucosa involving the gallbladder and biliary tree. Pediatr Radiol. 2003;33:129-32.

3. Xeropotamos N, Skopelitou AS, Batsis C, Kappas AM. Heterotopic gastric mucosa together with intestinal metaplasia and moderate dysplasia in the gall bladder: Report of two clinically unusual cases with literature review. Gut. 2001;48:719-23.

4. Yamamoto M, Murakami H, Ito M, Nakajo S, Tahara E. Ectopic gastric mucosa of the gallbladder: Comparison with metaplastic polyp of the gallbladder. Am J Gastroenterol. 1989;84:1423-6.
5. Egyedi L. Case of polypus of gallbladder containing an aberrant gastric mucous membrane. Gyogyaszat. 1934;74:596-9.

6. Hayama S, Suzuki Y, Takahashi M, Hazama K, Fujita M, Kondo S, Katoh H. Heterotopic gastric mucosa in the gallbladder: Report of two cases. Surg Today. 2010;40:783-7.

7. Hamazaki K, Fujiwara T. Heterotopic gastric mucosa in the gallbladder. J Gastroenterol. 2000;35:376-81.

8. Isik I, Sezer C, Dursun A. Gastric heterotopia in the gallbladder: A case report. Turk J Gastroenterol. 2002;13:172-4.

9. Boyle L, Gallivan MV, Chun B, Lack EE. Heterotopia of gastric mucosa and liver involving the gallbladder. Report of two cases with literature review. Arch Pathol Lab Med. 1992;116:138-42.

10. Ishikawa $\mathrm{O}$, Ohhigashi $\mathrm{H}$, Imaoka $S$, Nakaizumi A, Kitamura T, Sasaki Y, Shibata T, Wada A, Iwanaga T. The difference in malignancy between pedunculated and sessile polypoid lesions of the gallbladder. Am J Gastroenterol. 1989;84:1386-90.

11. Ferrell L, Kakar S. Tumors of the liver, gallbladder and biliary tree. In: Fletcher DM, editor. Diagnostic histopathology of tumors. 3rd ed. Philadelphia:Churchill Livingstone Elsevier; 2007.445-9. 